\title{
HUBUNGAN TINGKAT PENGETAHUAN DENGAN PERILAKU PERIKSA PAYUDARA SENDIRI (SADARI) PADA MAHASISWI FAKULTAS KEPERAWATAN UNKLAB
}

\author{
KNOWLEDGE RELATIONSHIPS BELOW USING BEHAVIOR BEHAVIOR (BEAUTY) \\ BEHAVIOR IN STUDENTS NURSING FACULTY UNKLAB
}

\author{
Nova Gerungan \\ Fakultas IImu Keperawatan, Universitas Klabat Airmadidi \\ Email: nova.gerungan@unklab.ac.id
}

\begin{abstract}
ABSTRAK
Pendahuluan: Periksa payudara sendiri atau SADARI merupakan salah satu upaya dini yang dapat dilakukan untuk mencegah kanker payudara pada wanita. Salah satu hal yang mendasari perilaku adalah pengetahuan seseorang. Pengetahuan merupakan hasil dari tahu dan ini terjadi setelah seseorang melakukan pengindraan terhadap objek tertentu, perilaku yang di dasari pengetahuan akan bertahan lama di bandingkan dengan yang tidak di dasari oleh pengetahuan. Mahasiswi Keperawatan UNKLAB sudah mendapatkan pelajaran dan informasi tentang SADARI, namun masih terdapat mahasiswi yang tidak melakukannya. Tujuan: Meningkatkan tingkat kesadaran akan pentingnya SADARI untuk pencegahan kanker dini. Metode: penelitian yang di gunakan dalam penelitian ini adalah Cross-sectional, populasi dalam penelitian ini adalah semua mahasiswi keperawatan tingkat IV UNKLAB, pengambilan sampel di lakukan dengan cara total sampling dengan jumlah mahasiswi 48 orang. Pengumpulan data menggunakan kuesioner skala Guttman. Analisa univariate menggunakan presentasi pada variable pengetahuan dan perilaku dan analisa bivariate menggunakan Spearman rank. Hasil: penelitian menunjukkan sebagian besar mahasiswi memiliki pengetahuan SADARI yang sedang $42(87,5 \%)$ dan perilaku SADARI yang cukup $25(54,2 \%)$. Tidak ada hubungan yang signifikan tingkat pengetahuan dengan perilaku SADARI mahasiswi Fakultas Keperawatan UNKLAB dengan $p$ value $0,235(>0,05)$. Keeratan hubungan antara tingkat pengetahuan dan perilaku SADARI memiliki nilai keeratan $-0,175$ yang berarti arah hubungan negatif. Diskusi: Mahasiswa Fakultas Keperawatan UNKLAB di harapkan dapat mengaplikasikan ilmu tentang SADARI yang sudah di peroleh.
\end{abstract}

Kata Kunci: Pengetahuan, Perilaku, SADARI

\section{ABSTRACT}

Introduction: Breast Self-Examination or BSE is one of the early efforts that can be done to prevent breast cancer in women. One of the things that motivates behavior is one's knowledge. Knowledge is the result of knowing and this occurs after a person sense to a particular object, the behavior based on knowledge will last long compared with that is not based on knowledge. Nursing Student UNKLAB has acquired lessons and information about BSE, but there are still students who do not practice it. Purpose: Increase the level of awareness of the importance of cancer prevention for early diagnose. Method: The research method used in this study is Cross-sectional, the population in this study were all senior nursing students UNKLAB, sampling is done by total sampling with the number of female students 48 people. Data collection using a Guttman scale questionnaire. Univariate analysis using presentations on knowledge and behavioral variables and bivariate analysis using Spearman rank. Result: The results showed that most of the students had knowledge of BSE which was $42(87,5 \%)$ and BSE behavior was adequate $25(54,2 \%)$. There is no significant relationship of knowledge level with the behavior of BSE of female students of Faculty of Nursing UNKLAB with $p$ value 0,235 (>0,05). The closeness of the relationship between knowledge level and behavior of BSE has a value of closeness - 0.175 which means negative relationship. Discussion: Faculty of Nursing UNKLAB students are expected to apply the knowledge about BSE that has been obtained.

Key Words: Knowledge, Behavior, BSE
JURNAL

SKOLASTIK KEPERAWATAN

Vol, 3, No. 2

Juli - Desember 2017

ISSN: $2443-0935$

E-ISSN 2443 - 1699 


\section{PENDAHULUAN}

Masa remaja merupakan tahap transisi dari masa kanak-kanak ke masa dewasa. Pada tahap ini sering remaja tidak menyadari bahwa suatu tahap perkembangan sudah dimulai, dimana remaja akan mengalami perubahan fisik, emosional dan sosial. Perubahan fisik dan biologis yang terjadi dikontrol oleh hormon pertumbuhan. Pada wanita, hormon tersebut berperan untuk permulaan proses ovulasi dan menstruasi dan pertumbuhan payudara. Oleh karena itu, sudah seharusnya para remaja mulai memperhatikan perubahan yang terjadi khususnya pada payudara dan kesehatannya (Bowden \& Greenberg, 2010)

Berdasarkan data WHO penyakit kanker merupakan penyebab kematian terbanyak di dunia, di mana kanker sebagai penyebab kematian nomor 2 di dunia sebesar $13 \%$ setelah penyakit kardiovaskular. Di Indonesia, berdasarkan data Riset Kesehatan Dasar (Riskesdas) tahun 2013, prevalensi kanker di Indonesia adalah 1,4 per 1000 penduduk. Kanker tertinggi di Indonesia pada perempuan adalah kanker payudara dan kanker leher rahim. Insiden kanker di Indonesia 134 per 100.000 penduduk dengan insiden tertinggi pada perempuan adalah kanker payudara sebesar 40 per 100.000 penduduk (KemenKes, 2015).

Tidak ada satu pun penyebab yang spesifik dari kanker payudara. Sebaliknya serang-kaian faktor genetik, hormonal, dan kemungkinan kejadian lingkungan dapat menunjang terjadinya kanker (Abdullah, Tangka \& Rottie, 2013). Penyebab kanker

belum dapat dipastikan karena bersifat multifaktorial, faktor resiko misalnya riwayat keluarga, riwayat tumor, belum pernah menyusui, konsumsi lemak tinggi, konsumsi alkohol (Lestianingrum, 2013).

Kementrian kesehatan RI (2015) menyatakan bahwa gerakan pencegahan dan deteksi dini kanker pada perempuan Indonesia sementara di laksanakan selama 5 tahun di seluruh Indonesia seperti kegiatan promotif, preventif, deteksi dini, dan tindak lanjut. Salah satu contoh intervensi yang dapat di lakukan adalah berupa deteksi dini dan skrining, sehingga dapat menurunkan tingkat stadium agar dapat memperpanjang tingkat kelang-sungan hidup serta menurunkan angka kematian.

Pengetahuan perempuan tentang risiko dan manfaat dari deteksi dini kanker payudara berpengaruh positif terhadap keyakinan mereka tentang kesehatan, sikap, dan perilaku, sehingga perawatan kesehatan professional dapat mengembangkan program kesehatan payudara yang efektif (Erbil \& Bolukbas, 2012). Dengan adanya pengetahuan yang cukup diharapkan para remaja akan mampu memotivasi diri mereka untuk melakukan tindakan yang berkaitan dengan upaya pencegahan dini (Abdullah, Tangka \& Rottie, 2013).

Salah satu upaya deteksi dini yang dapat di lakukan secara mandiri yaitu dengan perilaku periksa payudara sendiri (SADARI). Prosedur ini sederhana dan hanya memerlukan sedikit waktu namun harus di lakukan dengan sikap yang benar untuk mencapai tujuan yang diinginkan (Abdullah, Tangka \& Rottie, 2013). SADARI merupakan pemeriksaan payudara yang mudah jika dibandingkan dengan pemeriksaan oleh tenaga kesehatan maupun mammografi karena terdapat hubungan yang positif dan 
signifikan antara tingkat pengetahuan kanker payudara dan dengan perilaku SADARI (Lubis, 2010).

Hasil wawancara yang di lakukan oleh peneliti pada 10 mahasiswi keperawatan di Fakultas Keperawatan, Universitas Klabat di dapati bahwa hanya dua orang yang secara rutin melakukan SADARI. Sebagai mahasiswi keperawatan di harapkan sudah dapat melakukan deteksi dini dengan SADARI. Berdasarkan latar belakang masalah tersebut maka peneliti mengambil masalah penelitian yaitu "Hubungan tingkat pengetahuan dengan perilaku periksa payudara sendiri pada mahasiswi fakultas keperawatan Unklab”.

\section{BAHAN DAN METODE}

Metode penelitian yang di gunakan dalam penelitian ini adalah penelitian Crosssectional, yaitu jenis penelitian yang menekankan waktu pengukuran data variable independen dan dependen hanya satu kali pada satu saat (Nursalam, 2009). Variabel dependen pada penelitian ini adalah perilaku SADARI dan variabel Independen adalah tingkat pengetahuan tentang SADARI. Hipotesis penelitian ini adalah H0: tidak terdapat hubungan yang signifikan tingkat pengetahuan dan perilaku periksa payudara sendiri (SADARI) pada mahasiswi Fakultas Keperawatan Unklab.

Populasi dalam penelitian ini adalah mahasiswi Fakultas Keperawatan ajaran 2016/2017. Sampel penelitian di ambil dengan cara total sampling, dimana semua mahasiswi Fakultas Keperawatan Unklab tahun ajaran 2016/2017 yang berjumlah 48 orang di ikutsertakan dalam penelitian. Kriteria inklusi dalam penelitian ini adalah mahasiswi Fakultas Keperawatan Unklab, jenis kelamin wanita, usia 19-21 tahun. Sedangkan kriteria eksklusi penelitian ini adalah mahasiswi yang berhalangan hadir saat penelitian berlangsung.

Instrumen yang digunakan dalam penelitian ini di adaptasi dari penelitian Angesti Nugraheni yang sudah diuji validitas dan reliabilitas. Hasil dari uji reliabilitas item pernyataan mengenai pengetahuan tentang SADARI nilai 0,949 dan hasil uji reliabilitas pertanyaan mengenai perilaku SADARI nilai 0,901. Untuk mengidentifikasi pengetahuan responden tentang kanker payudara dan SADARI, kuesioner terdiri dari 48 item pernyataan dengan kategori "Benar dan Salah" dan diberikan skor 1 dan 0 . Selanjutnya untuk mengidentifikasi perilaku responden tentang SADARI, kuesioner terdiri dari 14 item pertanyaan pilihan ganda menggunakan 4 skala penilaian dengan pilihan: Selalu, Sering, Kadang dan Tidak pernah.

Analisa yang digunakan untuk mengukur tingkat pengetahuan dan perilaku responden menggunakan rumus:

$$
P=\frac{f}{n} \times 100 \%
$$

Keterangan: $\mathrm{P}=$ Persentase $\mathrm{f}=$ Jumlah jawaban sesuai dengan yang dianjurkan $n$ $=$ Jumlah skor maksimal

Hasil persentase pengetahuan selanjutnya akan di masukkan ke dalam kategori:

1. Tinggi, apabila didapatkan $76 \%$ $100 \%$

2. Sedang, apabila didapatkan 56\% $75 \%$

3. Rendah, apabila didapatkan $<56 \%$

Untuk perilaku dikategorikan menjadi tiga yaitu:

1. Baik, apabila didapatkan $76 \%$ $100 \%$

2. Cukup, apabila didapatkan 56\% $75 \%$

3. Kurang, apabila didapatkan $<56 \%$ 
Analisis bivariat pada penelitian ini untuk menganalisis hubungan antara variabel, menggunakan rumus korelasi spearman rank dengan tingkat kepercayaan 95\% dengan derajat kesalahan $5 \% \quad(\mathrm{p}$ signifikan $<0,05$ ).

\section{HASIL DAN PEMBAHASAN}

Hasil penelitian mengenai gambaran tingkat pengetahuan responden tentang SADARI dilakukan melalui pengumpulan data menggunakan kuesioner. Gambaran tingkat pengetahuan tersebut dapat dilihat pada tabel 1 .

Tabel 1. Distribusi Frekuensi Tingkat Pengetahuan SADARI

\begin{tabular}{lll}
\hline $\begin{array}{l}\text { Tingkat } \\
\text { Pengetahuan }\end{array}$ & Frekuensi & $\begin{array}{l}\text { Persentasi } \\
(\%)\end{array}$ \\
\hline Rendah & 3 & 6,3 \\
Sedang & 42 & 87,5 \\
Tinggi & 3 & 6,3 \\
\hline
\end{tabular}

Berdasarkan tabel 1 dapat di ketahui bahwa responden dengan tingkat pengetahuan tentang SADARI tinggi sejumlah $3(6,3 \%)$, tingkat pengetahuan tentang SADARI sedang sejumlah 42 $(87,5 \%)$ dan tingkat pengetahuan tentang SADARI rendah sejumlah 3 (6,3\%). Dapat di simpulkan bahwa sebagian besar mahasiswi Keperawatan Unklab memiliki tingkat pengetahuan yang sedang mengenai cara untuk melakukan deteksi dini kanker payudara yaitu dengan melakukan pemeriksaan payudara sendiri atau SADARI.

Pengetahuan merupakan hasil dari tahu dan ini terjadi setelah seseorang melakukan pengindraan terhadap objek tertentu, dalam hal ini proses pengindraan terjadi melalui pancaindra manusia. Sebagian besar pengetahuan manusia diperoleh melalui penglihatan dan pendengaran, sehingga pengetahuan merupakan domain yang sangat penting dalam membentuk tindakan seseorang (Efendi \& Makhfudli, 2009).

Dalam hal ini pengetahuan para mahasiswi keperawatan Unklab di dapatkan melalui proses pembelajaran di kelas, selain itu mahasiswa juga dituntut untuk memperoleh informasi atau pelajaran tidak dari dosen saja tapi di anjurkan untuk memperoleh pengetahuan juga dari berbagai sumber seperti buku, jurnal dan artikel. Para mahasiswi keperawatan nantinya akan menjadi seorang perawat profesional, untuk itu diharapkan harus memiliki pengetahuan yang baik mengenai SADARI.

Hasil penelitian mengenai gambaran perilaku responden tentang SADARI dilakukan melalui pengumpulan data menggunakan kuesioner. Gambaran perilaku tersebut dapat dilihat pada tabel 2.

Tabel 2. Distribusi Frekuensi Perilaku SADARI

\begin{tabular}{lll}
\hline $\begin{array}{l}\text { Perilaku } \\
\text { SADARI }\end{array}$ & Frekuensi & $\begin{array}{l}\text { Presentasi } \\
(\%)\end{array}$ \\
\hline Kurang & 14 & 29,2 \\
Cukup & 26 & 54,2 \\
Baik & 8 & 16,7 \\
\hline
\end{tabular}

Distribusi perilaku responden dalam melakukan pemeriksaan payudara sendiri meliputi perilaku SADARI baik sejumlah $8(16,7 \%)$, perilaku SADARI yang cukup baik sejumlah $26(54,2 \%)$ dan perilaku SADARI yang kurang baik sejumlah 14 $(29,2 \%)$.

Menurut Notoatmodjo (2012) perilaku merupakan respon dari individu akibat dari adanya stimulus atau rangsangan dari luar. Salah satu cara yang mudah dan efisien untuk dapat mendeteksi kelainan payudara oleh diri sendiri adalah dengan 
adanya perilaku untuk pemeriksaan payudara sendiri (SADARI) atau Breast Self Examination (BSE) (Nugraheni, 2010). Hasil penelitian diperoleh bahwa sebagian besar responden memiliki perilaku yang cukup dalam melakukan pemeriksaan payudara sendiri sebagai deteksi dini kanker payudara. Hal ini dapat disebabkan karena para mahasiswi yang menempuh pendidikan dalam bidang kesehatan khususnya keperawatan telah memperoleh pengetahuan tentang SADARI, sehingga akan cenderung memiliki perilaku yang baik dalam hal pencegahan penyakit.

Namun dari hasil penelitian ini juga didapati bahwa 14 (29,2\%) mahasiswi masih memiliki perilaku yang kurang tentang SADARI. Menurut Nugrahini, Anna \& Emaliyawati (2012) faktor yang menyebabkan sehingga seseorang tidak melakukan SADARI adalah akibat kurang percaya diri, takut menemukan kelainan, tidak punya waktu dan menganggap SADARI tidak perlu.
Pada tabel 3 dapat dilihat hasil analisis hubungan tingkat pengetahuan dengan perilaku SADARI pada mahasiswa keperawatan Unklab. Hasil analisis menunjukkan bahwa tidak terdapat responden yang memiliki pengetahuan rendah dan perilaku yang kurang mengenai SADARI, namun terdapat 13 ( $27,8 \%$ ) responden yang memiliki tingkat pengetahuan sedang tentang SADARI dengan perilaku yang kurang, untuk tingkat pengetahuan tinggi terdapat 1 $(2,08 \%)$ responden dengan perilaku yang kurang.

Hasil analisis pada kategori selanjutnya dapat dilihat bahwa terdapat $2(4,16)$ responden yang memiliki tingkat pengetahuan rendah tentang SADARI dengan perilaku yang cukup dan terdapat $22(45,83 \%)$ responden dengan tingkat pengetahuan SADARI sedang dengan perilaku yang cukup, untuk tingkat pengetahuan tinggi terdapat $2(4,16 \%)$ responden dengan perilaku yang cukup tentang SADARI.

Tabel 3. Distribusi Frekuensi Hubungan Tingkat Pengetahuan SADARI dengan Perilaku SADARI

\begin{tabular}{|c|c|c|c|c|c|c|}
\hline \multirow{2}{*}{$\begin{array}{l}\text { Tingkat } \\
\text { Pengetahuan }\end{array}$} & \multicolumn{3}{|c|}{ Perilaku SADARI } & \multirow[b]{2}{*}{ Total } & \multirow{2}{*}{$\begin{array}{l}\text { Correlation } \\
\text { coefficient }\end{array}$} & \multirow[t]{2}{*}{$p$ value } \\
\hline & $\begin{array}{l}\text { Kurang } \\
\text { (f) (\%) }\end{array}$ & $\begin{array}{l}\text { Cukup } \\
\text { (f) (\%) }\end{array}$ & $\begin{array}{l}\text { Baik } \\
\text { (f) } \quad(\%)\end{array}$ & & & \\
\hline Rendah & $0(0)$ & $2(4,16)$ & $1(2,08)$ & $3(6,25)$ & -.175 & .235 \\
\hline Sedang & $13(27,08)$ & $22(45,83)$ & $7(14,58)$ & $42(87,5)$ & & \\
\hline Tinggi & $1(2,08)$ & $2(4,16)$ & $0(0)$ & $3(6,25)$ & & \\
\hline Total & $14(29,16)$ & $26(54,16)$ & $8(16,66)$ & $48(100)$ & & \\
\hline
\end{tabular}

Analisis selanjutnya bahwa sejumlah 1 $(2,08 \%)$ responden memiliki pengetahuan yang rendah tentang SADARI namun perilakunya baik, 7 $(14,58 \%)$ responden memiliki pengetahuan sedang tentang SADARI dan memiliki perilaku yang baik dan tidak terdapat responden yang memiliki tingkat pengetahuan tinggi dengan perilaku yang baik tentang SADARI.
Hasil uji statistik untuk menguji hubungan tingkat pengetahuan tentang SADARI dengan perilaku SADARI menggunakan rumus spearman's rank, diperoleh nilai signifikan $p$ value $=0,235$ $>$ 0,05. Hasil ini menunjukkan penerimaan pada pernyataan H01: tidak terdapat hubungan yang signifikan tingkat pengetahuan dengan perilaku SADARI pada mahasiswa Fakultas Keperawatan Unklab. Hal ini dapat 
disebabkan oleh faktor lain yang mempengaruhi perilaku seperti sikap, kepercayaan, pengetahuan dan sumber daya (Notoatmodjo, 2012).

Hubungan antara tingkat pengetahuan dan perilaku SADARI memiliki nilai keeratan - 0,175 yang berarti arah hubungan negatif, dapat disimpulkan bahwa mahasiswi yang memiliki pengetahuan tentang SADARI belum tentu melakukan SADARI secara rutin. Hal ini sesuai dengan penelitian Alwan, Al-Diwan, Al-Attar dan Eliesa (2012) yang menyatakan bahwa para wanita yang sudah memiliki pengetahuan tentang SADARI, namun tidak pernah mempraktekkan teknik ini, karena tidak memiliki rasa percaya diri dan ketakutan mendeteksi adanya benjolan dipayudara.

Perubahan perilaku akan terjadi apabila ada penerimaan perilaku baru atau adopsi perilaku melalui proses yang didasarkan pada pengetahuan, kesadaran dan sikap positif maka perilaku tersebut akan bertahan lama, sebaliknya apabila perilaku tidak didasari oleh pengetahuan dan kesadaran, maka perilaku tersebut tidak akan berlangsung lama (Efendi \& Makhfudli, 2009).

Hasil analis selanjutnya didapati bahwa masih terdapat $13(27,08 \%)$ responden yang memiliki tingkat pengetahuan yang sedang dengan perilaku SADARI yang kurang baik. Hal ini dapat disebabkan karena adanya pengaruh sosial dan budaya serta norma yang dianut, karena SADARI dianggap melanggar norma kesopanan (Latif, 2014). Menurut AlAzmy, Alkabas, Almutawa, Ismaiel, Makboul dan El-Shazly (2013) bahwa faktor lain yang dapat menyebabkan kurangnya perilaku SADARI karena siklus menstruasi yang tidak teratur. SADARI sebaiknya dilakukan setelah menstruasi yaitu hari ke tujuh sampai sepuluh terhitung hari pertama haid, karena pada saat ini pengaruh hornom estrogen dan progesteron sangat rendah dan jaringan kelenjar payudara tidak membengkak, sehingga mudah untuk diketahui ada tidaknya benjolan (Manuaba, 2010).

\section{KESIMPULAN}

Berdasarkan hasil penelitian dapat disimpulkan bahwa sebagian besar mahasiswi tingkat IV Fakultas Keperawatan Unklab memiliki tingkat pengetahuan yang sedang $42(87,5 \%)$ tentang SADARI dan $26 \quad(54,2 \%)$ mahasiswi memiliki perilaku SADARI yang cukup baik. Hasil uji statistik didapati bahwa tidak terdapat hubungan yang signifikan antara tingkat pengetahuan dengan perilaku SADARI, hal ini dapat disebabkan kurangnya percaya diri, takut menemukan kelainan, tidak punya waktu dan menganggap SADARI tidak perlu. Selain itu faktor sosial budaya, riwayat keluarga, usia dan tingkat pendidikan juga dapat menjadi faktor yang mempengaruhi hubungan pengetahuan dan perilaku SADARI.

Hasil penelitian ini diharapkan dapat memberi masukan bagi profesi keperawatan agar lebih meningkatkan promosi kesehatan tentang SADARI, agar para mahasiswi dapat dibekali mengenai informasi pencegahan kanker secara dini, sehingga mereka dapat melakukan SADARI secara mandiri, baik untuk dirinya sendiri maupun untuk melaksanakan tanggung jawab dalam mendidik klien. Selanjutnya diharapkan penelitian ini dapat menjadi acuan untuk penelitian selanjutnya mengenai faktor yang menjadi latar belakang dilakukannya SADARI.

\section{DAFTAR PUSTAKA}

Abdullah. N., Tangka. J \& Rottie. J. (2013). Hubungan pengetahuan tentang kanker payudara dengan 
cara periksa payudara sendiri pada mahasiswi semester IV program studi ilmu keperawatan fakultas kedokteran Universitas Sam Ratulangi. Diakses tanggal 5 Februari 2017. http://ejournal.unsrat.ac.id/index.p hp/jkp/article/viewFile/2223/1780

Alwan, N.A.S., Al-Diwan, J, K,A., AlAttar, W. M \& Eliessa, R. A. (2012).

Knowledge, attitude \& practice towards breast cancer \& breast self-examination in Kirkuk University, Iraq. Asia Pasific Journal of Reporduction. 1(4) 308311

Al-Azmy, S. F., Alkhabbaz, A., Almutawa, H. A., Ismaiel, A. E., Makboul, G \& El-Shazly, M.K. (2013). Practicing breast selfexamination among women attending primary health care in Kuwait. Alexandria Journal of Medicine. 49, 281-286

Bowden, V.R \& Greenberg, C.S. (2010). Children and their families the continuum of care. $2^{\text {nd }} \mathrm{Ed}$. Philadelphia: Lippincott Williams \& Wilkins

Erbil, N \& Bolukbas. (2012). Beliefs attitudes and behavior of Turkish women about breast cancer and breast self-examination according to a Turkish version of the Champion Health Belief Model Scale. Asian Pacific Journal Cancer Prevention

KemenKes. (2015). Panduan program nasional gerakan pencegahan dan deteksi dini kanker leher rahim dan kanker payudara. Diakses tanggal

Februari

2017. http://www.pptm.depkes.go.id/cm s/frontend/ebook/Buku_Panduan

Pelaksanaan_IVA-

SADANIS_2015.pdf

Lubis, A.S. (2010). Hubungan tingkat pengetahuan tentang kanker payudara dan SADARI dengan perilaku SADARI pada mahasiswi fakultas psikologi universitas sumatera utara angkatan 2008. Diakses tanggal 5 Februari 2017. http://repository.usu.ac.id/bitstrea $\underline{\mathrm{m} / 123456789 / 31861 / 7 / \text { Cover.pdf }}$

Latif, R. (2014). Knowledge and attitude of Saudi female students towards breast cancer: A cross-sectional study. Journal of Taibah University Medical Sciences. 9(4), 328-334

Nugraheni, A. (2010). Hubungan tingkat pengetahuan tenang SADARI dengan perilaku SADARI sebagai deteksi dini kanker payudara pada mahasiswi D IV kebidanan FK UNS. Diakses tanggal 5 Februari 2017.

https://digilib.uns.ac.id/dokumen/ download

Efendi, F \& Makhfudli. (2009). Keperawatan kesehatan komunitas teori dan praktik dalam keperawatan. Jakarta: Salemba Medika

Manuaba. I. (2010). Ilmu kebidanan, penyakit kandungan dan KB untuk pendidikan. Ed2. Jakarta: EGC

Notoatmodjo, S. (2012). Promosi kesehatan dan perilaku kesehatan. Jakarta: Rineka Cipta

Nursalam. (2009). Metodologi penelitian ilmu keperawatan. Jakarta: Salemba Medika 
Nugrahini, D. S, Anna, A \& http://jurnal.unpad.ac.id/ejournal/a Emaliyawati, E. (2012). Hubungan rticle/view/729/775 tingkat pengetahuan dengan perilaku SADARI pada mahasiswi fakultas ilmu keperawatan universitas Padjadjaran. Diakses tanggal 20 Desember 2017 